\title{
Holism: A Concept Analysis
}

\section{Eileen McMillan ${ }^{1}$, Natalina Stanga ${ }^{2}$ and Sharon L. Van Sell ${ }^{3,}$}

${ }^{1}$ Graduate Nursing Program, Texas Woman's University, United States of America ${ }^{2}$ Graduate Nursing Program, Texas Woman's University, United States of America

${ }^{3}$ Professor, The Houston J. and Florence A. Doswell College of Nursing, Texas Woman's University, United States of America

\section{Abstract}

The concept of holism is not new to the world of healthcare in other countries, but in the practice of traditional Western medicine, holism is still emerging. Holism is including the whole being, mind, body, and soul, acknowledging that the whole is more than a sum of the parts. The concept of holism was analyzed according to the Walker and Avant methodology to guide nursing practice to offer more comprehensive care to patients. Attributes of the concept are total, balanced, mind, body, and spirit, and whole. Antecedents were analyzed and are knowledge, understanding, relationships, and intention. Furthermore, the identified consequences of the concept were healing, peace, wellness, and Zen. To demonstrate holism in nursing a model, borderline, and contrary casesare laid out. Finally, a discussion about how the concept of holism enhances care given by the advanced practice nurse. broaden the perspective of what constitutes the essence of a human being, leading to a multidimensional approach to patient care.

\section{Holism Relates Theory to Practice}

According to Walker and Avant [2], theory development "provides a way to identify and express key ideas about the essence of practice" (p. 3). Theory helps the discipline of nursing by providing a more complete and insightful disposition to the practice of nursing. The concept of holism is deeply rooted in the discipline of nursing and is not new to the practice of nursing. Many nursing theories have used holism to relate theory to practice. The concept of holism was present in Martha Rogers' theory of science of unitary and irreducible human beings. According to Rogers [3], "Man is a unified whole possessing integrity and manifesting characteristics that are more than and different from the sum of his parts" (p. 47). The focus of the theory was on the interconnectedness of the unitary human being and the environment. A person is an indivisible, pan-dimensional energy field representing a whole that cannot be divided into parts[3]. The human energy field must coexist within the environment which is also an energy field identified by pattern [3].

Another theorist that used holism as a basis for theory development is Jean Watson. The theory of human caring/caring science focused on caring and love as universal forces [4]. Watson recognized the importance of the spiritual and ethical dimensions of the human caring process. The transpersonal caring relationship goes beyond the ego to a higher spiritual caring created by caring moments [4]. Heart-centered caring based on practicing and honoring wholeness of mind, body, and spirit of self. Watson's transpersonal caring relationship incorporated inner harmony by maintaining balance [4] The principles of the theory of human caring/caring science aligned with the tenets of holism.

"Corresponding Author: Dr. Sharon L Van Sell, The Houston J and Florence A Doswell College of Nursing, 5500 Southwestern Medical Avenue, \#7209, Dallas, Texas, 75235-7299, USA, Tel: 1-864-275-3527, Fax: 214-689-6539; E-mail: svansell@twu.edu

Citation: McMillan E, Stanga N, Van Sell SL (2018) Holism: A Concept Analysis. Int J Nurs Clin Pract 5: 282. doi: https://doi.org/10.15344/2394-4978/2018/282

Copyright: () 2018 Van Sell et al. This is an open-access article distributed under the terms of the Creative Commons Attribution License, which permits unrestricted use, distribution, and reproduction in any medium, provided the original author and source are credited. 


\section{Definitions and Uses of Holism}

The word holism comes from the Greek holo- meaning "whole, entire, complete" [5]. According to dictionary.com, the suffix -ism is "used to form action nouns from verbs" [6]. The general definition of holism as stated by the Merriam-Webster Online Dictionary is "a theory that the universe and especially living nature is correctly seen in terms of interacting wholes (as of living organisms) that are more than the mere sum of elementary particles" [7]. The word holism was first coined by J.C. Smuts, a South African philosopher, in his book Holism and Evolution [8]. Smuts regarded holism as being "grounded in evolution and is an ideal that guides human development and of reductionism, which defines breaking something complicated down into straight forward parts [9]. Reductionism used by the medical practice as a principle foundation for understanding disease, but only takes the biology of the disease into account and does not address psychology, or behavioral components of disease [10]. Smuts argued that reductionism produces a view of the natural world that constitutes "a mere collection of disjecta membra, drained of all union or mutual relations, dead, barren, inactive, unintelligible" (p. 13) [8]. Reductionism does not take into account all the parts of the whole and therefore does not fully grasp the scope of an individual.

The concept of holism has roots in other disciplines as well. In the practice of nursing, holism is "treating of the whole person, taking into account mental and social factors, rather than just the symptoms of a disease" [11]. Holism opposes the medical model of reductionism. Furthermore, psychiatry defines holism as "an approach to the study of the individual in totality, rather than as an aggregate of separate physiologic, psychologic, and social characteristics" [12]. According to sociology, holism is "the principle that the whole is greater than the sum of its parts and a part cannot be understood independent of the whole" [13]. The APN utilizing the concept of holism will be able to understand patients on a deeper level and therefore give more wellrounded care.

\section{Attributes}

A key step in concept analysis is defining the attributes that make up a concept. Walker and Avant define attributes as "defining characteristics" of a concept (p. 162) [2]. The attributes of holism are total, balanced, mind, body, spirit and whole.

The word total means "the whole amount of something or the entirety" [14]. The premise of holism regards the human being as more than the sum of the parts. Understanding the individual requires looking at the total picture. Totality is the "whole set of elements that are meaningfully interrelated in such a way that the essence of each element can only be understood in its relation to the others" (para 13) [15]. A holistic approach coincides with the totality perspective since totality incites "the feeling of inability or unwillingness to break up an object into smaller objects" (p. 7) [16].

The idea of being balanced is central to holism. The parts of the individual must take equal precedent. Balanced means "to bring into or keep in equal or satisfying proportion or harmony" [17]. One part cannot be forsaken or else the parts will not fit together to form the whole. "When some of these structural parts suffer or operates with fault, then imbalance or disorder appears" (p.65) [18]. Creating balance is also central to traditional Chinese nursing practices. one's level of personality actualization" [8]. Holism is the opposite

According to Chinese philosophy, everything that exists has the two aspects of yin and yang [19]. Poor health is the result of an imbalance of yin and yang [19].

Mind, body, and spirit (MBS) are interconnected elements that make up the person and cannot be separated into individual parts. "The Nous, the Physical, and the Psyche cannot be independent parts, because of interconnections, a disturbance in one part affect the other parts, which are exhibited physically, psychically and mentally (noetic) depending on the part that suffers" (p. 77) [18]. Many cultures and religions utilize the MBS notion. MBS is explained by the following, 'mind' refers to 'mental processes,' while the body is said to include the physical, biological, and chemical aspects of an individual. Spirituality is defined variously as existential reality, connectedness, and energy" (p. 1756) [20].

Whole means "not divided or disjoined; in one unit" [21]. The concept of holism is based on the conglomerate of the whole. Dividing the whole into pieces as the medical practice does break the individual apart and is in no way an optimal approach to the understanding of an individual. The nurse practitioner tailors care for the whole person that addresses personal, social, environmental, and cultural factors [22]. A close nurse-patient collaborative relationship is established to provide care to the whole person that focuses on the patient's unique needs [22]. Broadening the focus to the whole person institutes the concept of patient-centered care that has emerged as an important force in the changing healthcare climate [22].

\section{Antecedents and Consequences}

Another important step in concept analysis is distinguishing appropriate antecedents and consequences of the concept. According to Walker and Avant, "antecedents are those events or incidents that must occur or be in place prior to the occurrence of the concept" (p.167) [2]. The applicable antecedents for the concept of holism are knowledge, understanding, relationships, and intention.

Without knowledge, one cannot begin to see and thus know an individual truly. Knowledge defined as "familiarity, awareness, or understanding gained through experience or study" [23]. Analysis and knowledge of self and personal beliefs is necessary to know another person. Additionally, the knowledge gained by one person varies widely from the knowledge another has amassed and thus determines how one sees the world. As Stiles points out, "One's perception, or how one comes to know and interpret information, reveals and shapes one's personal world view to a large extent" (p. 39) [24]. Without knowledge, holism could not exist.

The philosopher John Locke said "there is no understanding without knowledge" and he believed understanding is passive (p. 307) [25]. The definition of understanding is "personal opinion or interpretation of a subject" [26]. To understand, one must commit time to listening and reflecting. To understand others, one must know self first. Through understanding oneself, a deeper therapeutic relationship develops with others, and holistic care can truly emerge.

When one believes another understands them, a relationship can be formed [27]. The definition of relationship is as "an emotional or other connection between people [28]. A connection with others is essential to the practice of holism. A therapeutic relationship based on understanding facilitates holistic care delivery because once a relationship is established one can know what is important to making up the parts that compose the whole of the other.

Int J Nurs Clin Pract

ISSN: 2394-4978

IJNCP, an open access journal Volume 5. 2018. 282 
The final antecedent of holism is the intention, defined as "consciously committing to act in a definiteway" [29]. Intention takes planning, thought, and acting in a deliberate manner [30]. Without planning to look for the parts of an individual and assimilate them together into a whole, one may unknowingly focus on merely the parts. A conscious effort is necessaryto integrate all parts of an individual together.

Walker and Avant [2] stated, "Consequences, on the other hand, are those events or incidents that occur as a result of the occurrence of the concept-in other words, the outcomes of the concept" (p. 167). The consequences of holism are healing, peace, wellness, and Zen.

One outcome of holism is healing which can be defined in two ways: "to restore to health or soundness" and "to ease or relieve (emotional distress)" [31]. To heal is to become whole and according to Cowling, "In the practice of healing the focus is 'on establishing, achieving, or regaining a sense of cohesion' among the parts" (p.18) [32]. Therefore, holism and healing are one and the same. The job of the APN is to discover which parts of the whole are out of balance and focus on those accordingly.

Another outcome of holism is peace. Peace is "inner contentment and serenity" [33]. Traditional western medical practices do not leave patients with a feeling of peace, but rather a feeling being misunderstood by medical professionals, resulting in unrest. The ancient practices of Buddhism and Taoism regard attaining inner peace as the vital objective in life [34]. By practicing holism, the APN can help individuals achieve peace.

Wellness is "the state of being in good physical and mental health" [35]. Wellness is the active process of making daily decisions that lead to a healthy and fulfilling life. Sweeney and Witmer [36] developed a theoretical model called the wheel of wellness. The model identified several characteristics that correlated positively with healthy living, quality of life, and longevity. The life forces that affect wellness are family, religion, education, business, media, government, and community [36]. The wheel of wellness is a holistic model of wellness and prevention that summarized the view point of wellness from multiple disciplines. There is a paradigm shift away from care solely focused on disease and illness, and refocusing efforts on wellness. The nurse practitioner plays an active role in health promotion and disease prevention.

Borrowing from the ideas of the Buddhist culture, a state of Zen is usually associated with a sense of calm. As defined by Urban Dictionary, Zen is "a total state of focus that incorporates a total togetherness of body and mind" [37]. Zen is the quest to achieve the highest degree of self-knowledge that will result in peace of mind and comfort with self [38]. Holistic nursing practices incorporate a Zen modality of meditation to focus the mind on the here and now [38]. Nurses incorporate Zen modalities into the nursing care of difficultto-wean, mechanically ventilated patients [39]. The outcome was enhanced mind-body harmony that used controlled breathing and self-consciousness to achieve an optimal breathing pattern [39].

\section{Model Case}

As stated by Walker and Avant [2] "a model case is an example of the use of the concept that demonstrates all the defining attributes of the concept" (p. 163). Annie is an oncology nurse with a degree in anthropology who lived in India while doing research for her anthropology degree. While there she became very familiar with the culture. Annie is assigned to Mrs. X, a patient of Indian decent on the oncology unit. Mrs. X has only been in the US for one month and is noncompliant in her treatment. Annie sits down with Mrs. X to get to the bottom of Mrs. X's treatment noncompliance. Annie learns that Mrs. X will not eat the hospital food because the food is different from the traditional food of India. As a result, Mrs. X is losing weight and has a resultant poor nutritional status. Annie tells Mrs. X that the medical doctor (MD) plans to insert a nasogastric tube to help Mrs. X meet her nutritional goals, but Mrs. X refuses. Because Mrs. $\mathrm{X}$ is on neutropenic precautions, Annie understands the difficulty in bringing the traditional Indian food from home to the hospital. Annie collaborates with the dietitian, and with the MD's approval, formulates a plan to educate Mrs. X's family about proper food handling and provides a list of foods to avoid for neutropenic precautions, as well as emphasizing high protein, high-calorie count meal plans.

Additionally, Annie learns Mrs. X is experiencing pain management issues. Mrs. X explains to Annie that she does not have faith in the western medicine model and wants to use traditional Indian therapies to treat her cancer. Annie recognizes the impact of Mrs. X hurried introduction into the American model of treating disease, while Indian culture incorporates much more. Annie identifies that Mrs. $\mathrm{X}$ would benefit from inclusion in her treatment plan. Additionally, Annie collaborates with the MD to develop a plan incorporating traditional Indian pain management techniques as well as low dose narcotics. Mrs. X is still hesitant but accepts the plan. Annie later learns that Mrs. X has repeatedly been offered the services of the hospital chaplain and refused. As Mrs. X is new to the USA, she has not yet connected with a religious group of her culture. Annie knows the importance of spirituality in the Indian culture; Annie finds Mrs. X's an appropriate religious leader and arranges for a visit. At the end of the day, Annie finds Mrs. X crying in her room, very upset that the doctors rounded when the husband was not present. Annie recognizes Indian cultural customs use the family decision-making model. Therefore, Annie requested Mrs. X provide the doctors with the times her husband will be present to coordinate doctors rounds. By the end of the week, Mrs. X has gained half a pound, with her pain controlled. Annie feels confident she made a positive impact on Mrs. X's life.

\section{Borderline Case}

"Borderline cases are those examples or instances that contain most of the defining attributes of the concept being examined but not all of them" (p. 164) [2]. Discussed next is a borderline case.

Jane comes into the emergency department (ED) frequently for diabetic ketoacidosis (DKA). The nurse Molly knows Jane well and is aware that she is a borderline mentally disabled prostitute with type I diabetes. Jane uses drugs frequently, is not entirely coherent a few days, and then develops DKA. Molly is frustrated by having Jane as a patient because she cannot understand how Jane keeps letting her diabetes get out of control and scolds Jane for continued admissions to the ED. Jane relates a history of sexual abuse and states the only life she knows is selling her body for money. Molly is further infuriating by Jane even more because Molly was also sexually abused yet became a productive member of society. Molly knows that having type I diabetes is not Jane's fault; she was born with the condition, and that Jane's mental disability is part of the reason she keeps developing DKA. Molly begrudges Jane, thinking "She knows better than to miss her insulin doses!" Molly is defining Jane as one of her parts, mental 
retardation leading to the inability to care for herself, as opposed to looking at her as a whole. Knowing Jane has been offered drug rehab in the past but only stayed there a few days, Molly does not even offer or encourage Jane to go to rehab. Molly knows that any effort made educating Jane on proper diabetic self-care would be futile. So she skips the education part of the discharge as well. Jane is discharged later that day, and Molly is glad to see her go.

\section{Contrary Case}

According to Walker and Avant [2], "contrary cases are clear examples of 'not the concept' (p. 166). An example of a contrary case to the concept of holism involves Sarah, a staff nurse on a medicalsurgical floor. During report one morning, Sarah learns she will be assuming care of a 55-year-old male admitted for pancreatitis secondary to excessive alcohol use. The patient's chief complaint upon arrival to the emergency department was severe abdominal pain with nausea and vomiting. The patient has been on the medical-surgical floor for four days and constantly demanding pain medication and food despite being ordered nothing by mouth (NPO). The MD order for pain management is hydrocodone/acetaminophen (Norco) $10 / 325 \mathrm{mg}$ Q4hours for moderate pain (pain rating of 4-6/10) and hydromorphone (Dilaudid) $0.5 \mathrm{mg}$ Q2 hours for severe pain (pain rating 7-10/10). Sarah starts her day by introducing herself to the patient, performing a physical assessment, and discussing the plan of care. The patient angrily interrupts Sarah and says, "All I need from you is my Dilaudid and food. I have not eaten in four days!" Sarah explains that the MD order is NPO and that she will have to check the medication administration record (MAR) to see if the Dilaudid is due. Sarah leaves the room, checks the MAR, and sees the Dilaudid was given just one hour before, but the Norco is due for administration now. Sarah brings the Norco to the patient's room, but before entering, she observes the patient through the ajar door. The patient is laying in bed watching an episode of the Simpson's, laughing hysterically. Sarah does not think the patient appears to be in any pain or distress. Sarah enters the room, and the patient's demeanor immediately changes, and he angrily exclaims, "It's about time!" Sarah tries to administer the Norco,and the patient shouts "No, I want my Dilaudid and where is my breakfast?!" Sarah is now irritated and does not even think the patient is in fact in pain. Sarah tells him "The Dilaudid is not due, you just had it. You can have the Norco or nothing at all. And as for the food, you are NPO. Do you want the pain to get worse?!" Sarah immediately leaves the room and does not return to the patient's room despite multiple calls on the call light until the Dilaudidis due for administration.

\section{Empirical Referents}

Defining empirical referents is the last step in concept analysis and involves asking the question "If we are to measure this concept or determine its existence in the real world, how do we do so?" (p. 168) [2]. MBS is a defining attribute of the concept of holism and components that must be included for the APN to provide holistic, patient-centered care. Complementary and alternative medicine (CAM) is the use of therapies outside of conventional medicine practices that incorporate the MBS element of the concept of holism. According to Korkmaz, Tavslani, and Ozcelic [40] CAM is subdivided into five headings that include:

Cultural interventions (homeopathy, naturopathy, traditional Chinese medicine, and Ayurveda), body-mind interventions (music therapy, spiritual healing, psychological interviews, praying), treatments of biologic origin (herbs, diet support products, medical herbal tea, or animal parts such as shark cartilage), body-based interventions (massage, chiropractic manipulation, osteopathy), and energy treatments (Reiki, Qigong, electromagnetic therapies) (p. 88).

The CAM modalities to care related to higher quality of life scores [40]. In addition to the quality of life, the use of CAM applied to the treatment and prevention of many diseases. A study that investigated the use of CAM in cancer patients found that $7 \%$ to $64 \%$ of patients with a cancer diagnosis incorporated CAM [40]. The evidence from the study supports the holistic approach to care that incorporates the elements of MBS by the APN.

The spirituality component of the attribute of MBS is an integral part of the holistic care that leads to positive patient outcomes. Research has explored spiritual nursing interventions in the care of older adults with dementia [41]. Dementia is a devastating, progressive neurological disease that robs the affected individual of memories and true identity. Definition of spiritual nursing care is "the activity and way of being that brings spiritual quality of life, well-being, and function to clients" (p. 106) [41]. The literature suggests that spirituality in dementia patients leads to guidance, hope in the afterlife, and acceptance [41]. Spirituality results in decreased agitation and anxiety, which relates to an increase in quality of life [41]. High levels of spirituality correlate with lower morbidity and mortality and with a higher life expectancy of seven to eight years longer [41]. Specifically, the research found that rituals and music are key interventions for inclusion in the care of dementia patients. Rituals help dementia patients connect to deeply embedded unforgettable memories [41]. Music has shown to have remarkable effects causing a decrease in behavioral problems and invoking a sense of comfort from the ingrained nostalgia within the spiritual song [41]. Music can stimulate multiple parts of the brain, activating intact neurological pathways. The evidence suggests that the spiritual care provided by the APN is just as important as medical, pharmacological, and physical care provided.

Massage defined as the manipulation of soft tissues performed by the hands that have a positive effect on the vascular, muscular and nervous system [42]. Massage therapy recognized for the benefits of decreased pain, improved immune function, reduced anxiety and depression, relief of fatigue and nausea, and overall improvement in stress [42]. Massage with aromatherapy helped relieve short-term pain and anxiety with people with cancer [42]. Some of the attributed benefits of massage are to the power of physical touch [42]. The addition of aroma therapy with massage uses the essential oils of lavender rose, and chamomilecontributes to the positive outcomes [42].

\section{Impact of Holism in Advanced Nursing Practice}

A holistic APN incorporates CAM therapies in addition to traditional medical care as opposed to only concentrating on the reductionist interventions [43]. As healthcare changes and APN's play a more central role in providing healthcare, the APN has a unique opportunity to change the delivery of healthcare. Those in the healthcare profession are responsible for focusing on the patient's unique needs leading to a multidimensional approach to patient care. Widening the scope of practice to the whole person establishes the concept of patient-centered care that has been an ever-present focus on the emerging healthcare climate [22]. To practice holistic nursing, the APN must "develop a specific and expanded set of healing skills beyond those necessary to perform the reductionistic-technological 


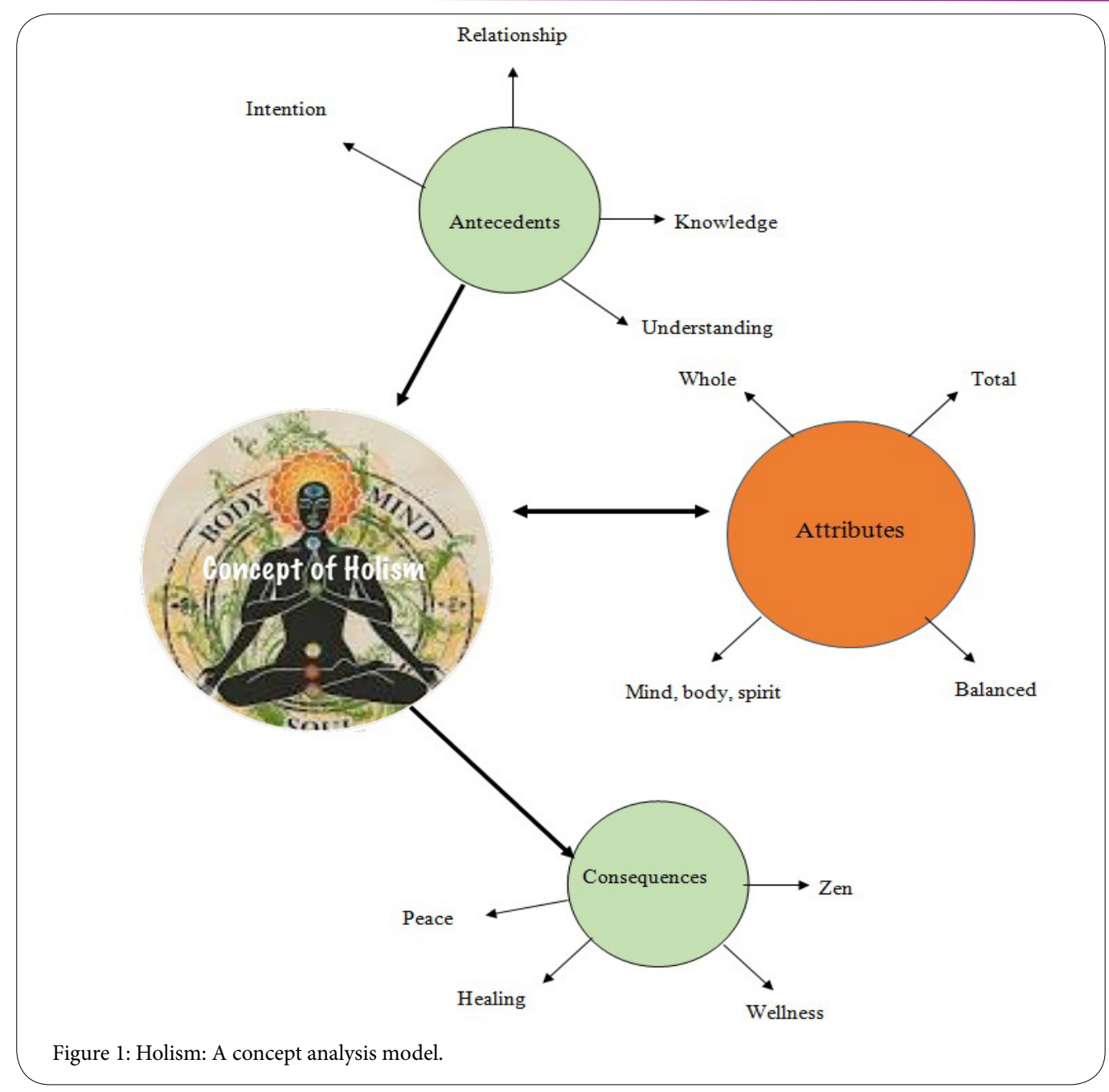

duties of most contemporary allopathic nursing practices" (p. 93) [43]. The APN must truly embrace CAM therapies in his or her personal life to carry the concept of holism into his or her nursing practice [43].

\section{Impact of Holism on Present Day Nursing Research}

Nursing scholars strive to reclaim nursing from the reductionist medical model and establish the nursing profession as a holistic science. The concept of holism impacts present day research efforts and serves as the philosophical groundwork for nursing theory. The rapid, dynamic changes occurring in healthcare have dictated a more comprehensive, holistic way of arriving at decisions than the traditional nursing process. Many of the founders of the profession of nursing developed theories to understand caring, healing, and the nature of the whole. Today the concept of holism influenced nurse scholars in their research endeavors. The American Holistic Nurses Association encourages holistic nursing research efforts to develop knowledge and provide evidence-based practice that is needed to transform healthcare into holistic care [44].

\section{Conclusion}

Figure 1 depicts an illustrative model for the concept analysis of holism. The figure portrays the interconnection of the attributes, antecedents, and consequences of the concept of holism. The concept analysis identified the attributes as (a) mind, body, spirit, (b) whole, (c) balanced, and (d) total. The antecedents of the concept of holism are (a) relationship, (b) intention, (c) understanding, and (d) knowledge. The consequences of the concept of holism are (a) peace, (b) Zen, (c) wellness, and (d) healing. Defining holism helps the APN better understand the foundational concept that guides the practice of nursing, which will ultimately lead to better care for the patient.

\section{Competing Interests}

The authors, McMillan and Stanga declare that they have no competing interests.

Dr. Van Sell declares she is co-author of the e-book The Evolving Essence of the Science of Nursing: The Complexity Integration Nursing Theory.

\section{Funding}

This article was published with support from Texas Woman's University Libraries' Open Access Fund.

\section{References}

1. Lawrence $\mathrm{HA}(2016)$ Holism vs. reductionism: Comparing the fundamentals of conventional and alternative medicinal modalities. Explore integrative medicine. 
2. Walker LO, Avant KC (2011) Strategies for theory construction in nursing (5 $5^{\text {th }}$ edition). Upper Saddle River, NJ: Prentice Hall.

3. Rogers ME (1970) An introduction to the theoretical basis of nursing. Philadelphia: F. A. Davis.

4. Watson J (2008) The philosophy and science of caring. Boulder: University Press of Colorado.

5. holo- (2010) Online etymology dictionary.

6. ism (2016) Dictionary.com unabridged.

7. Holism (2016) Merriam-Webster's online dictionary.

8. Smuts JC (1936) Holism and Evolution (3rd edition). London: MacMillan and Co., Limited.

9. Reductionism (2016) In Merriam-Webster online dictionary.

10. Turner PWD, Holroyd E (2016) Holism in osteopathy-Bridging the gap between concept and practice: A grounded theory study. International Journal of Osteopathic Medicine 22: 40-51.

11. Holism (2016) Oxford living dictionaries.

12. Holism (2002) McGraw-Hill concise dictionary of modern medicine.

13. Holism (2016) Open education sociology dictionary.

14. Total (2016) American Heritage Dictionary of the English Language (5th edition).

15. Stahl T, Lukács G (2016) In E.N. Zalta (Ed.). The Stanford Encyclopedia of Philosophy (Summer 2016 ed.).

16. Sapir E (1930) Totality. Language 6: 7-28.

17. Balanced (2016) American Heritage Dictionary of the English Language (5th edition).

18. Van Sell SL, Kalofissudis I (2002) The evolving essence of the science of nursing: Complexity integration nursing theory. E-book, 2nd Printing 2010. Athens, Greece: ICU Web Journal.

19. Hao T, Liu H, Yue S, Liu X (2011) Introducing traditional Chinese nursing A review of concepts, theories, and practices. Int Nurs Rev58: 319-327.

20. Mark GT, Lyons AC (2010) Maori healers' views on wellbeing: The importance of mind, body, spirit, family, and land. Soc Sci Med 70: 17561764.

21. Whole (2016) American Heritage Dictionary of the English Language (5th edition).

22. Povlsen L, Borup IK (2011) Holism in nursing and health promotion: distinct or related perspectives? - A literature review. Scand J Caring Sci 25: 798805 .

23. Knowledge (2016) American Heritage Dictionary of the English Language (5th edition).

24. Stiles KA (2011) Advancing nursing knowledge through complex holism. ANS Adv Nurs Sci 34: 39-50.

25. Condon BB (2010) Understanding-misunderstanding: A philosophical and theoretical exploration. Nurs Sci Q 23: 306-314.

26. Understanding (2016) American Heritage Dictionary of the English Language (5th edition).

27. Holoien DS, Bergsieker HB, Shelton JN, Alegre JM (2015) Do you really understand? Achieving accuracy in interracial relationships. J Pers Soc Psychol 108: 76-92.

28. Relationship (2016) American Heritage Dictionary of the English Language ( $5^{\text {th }}$ edition).

29. Intention (2016) Mosby's medical dictionary ( $8^{\text {th }}$ edition)

30. Stewart L (2011) Transformation and the power of intention. Gastroenterology Nursing 34: 196-197.

31. Healing (2016) American Heritage Dictionary of the English Language ( $5^{\text {th }}$ edition).

32. Cowling WR (2000) Healing as appreciating wholeness. ANS Adv Nurs Sci 22: 16-33.

33. Peace (2016) American Heritage Dictionary of the English Language (5 edition).

34. Liu X, Xu W, Wang Y, Williams JMG, Geng Y, et al. (2015) Can inner peace be improved by mindfulness training: A randomized controlled trial. Stress and Health 31: 245-254.
35. Wellness (2016) American Heritage Dictionary of the English Language (5 $5^{\text {th }}$ edition).

36. Sweeney TJ, Witmer JM (1991) Beyond social interest: Striving toward optimum health and wellness. Individual Psychology 47: 527-540.

37. Zen (2016) Urban dictionary.

38. Donnelley G (2011) On being present: A Zen perspective. Holist Nurs Pract 25: 173.

39. Thinhuatoey B, Songwathana P, Petpichetchian W (2016) The careintegrated concentration meditation program for apatient with weaning difficulty: A pilot study. Holist Nurs Pract 30: 201-210.

40. Korkmaz M, Tavslani N, Ozcelic H (2016) Use of complementary and alternative medicine and quality of life of patients. Holist Nurs Pract 30 : 88-95.

41. Ennis E, Kazer M (2013) The role of spiritual nursing interventions on improved outcomes in older adults with dementia. Holistic Nursing Practice 27: 106-113.

42. Shin E, Seo K, Lee S, Jang J, Jung Y, et al. (2016) Massage with or without aromatherapy for symptom relief in people with cancer. Cochrane Database Syst Rev 6: 1-71.

43. Clark CS (2012) Beyond holism: Incorporating an integral approach to support caring-healing-sustainable nursing practices. Holist Nurs Pract 26: 92-102.

44. American Holistic Nurses Association (2016) Holistic nursing research 